\title{
Yawning: Effects of stimulus interest
}

\author{
ROBERT R. PROVINE and HEIDI B. HAMERNIK \\ University of Maryland Baltimore County, Catonsville, Maryland
}

The hypothesis that subjects yawn more while observing uninteresting than while observing interesting stimuli was tested by comparing the yawns produced by 17 - to 19 -year-old college freshmen while they observed a 30-min rock video, a complex and interesting audiovisual stimulus, and a 30-min color-bar test pattern without an audio track, an unchanging and very uninteresting stimulus. Significantly more and longer yawns were produced during the uninteresting than during the interesting stimulus and males performed longer yawns than females. The folk belief that people yawn more during boring than interesting events was confirmed.

Yawning is characterized by gaping of the mouth that is accompanied by a long inspiration followed by a shorter expiration. Yawning is a behavior of the type called "stereotyped" or "fixed" by ethologists and is triggered by yet unspecified physiological states or "released" by witnessing yawns or yawn-related stimuli (Provine, 1986). Indeed, yawning may be the best example of a stereotyped action pattern and stimulus releaser in humans. Yawning is an obvious, common, and probably universal human act that is performed throughout the lifespan; however, there is much opinion but little empirical evidence concerning why yawning occurs, what function yawning serves, and what environmental circumstances modulate yawning rate (Barbizet, 1958; Heusner, 1946; Provine, 1986). For example, the association of yawning with low levels of arousal (Kataoka, 1975; Kishida, 1973; Sakai \& Takahashi, 1975) has led to speculation about the role of yawning in increasing alertness. It also is commonly believed that more yawning occurs while observing uninteresting than interesting events. This may be the basis for the recognition of the yawn as a paralinguistic signal for boredom. The popular press acknowledges that the yawn is a sign of boredom by referring to boring speeches and uninspiring artistic or sports events as "yawners."

The present study evaluated the hypothesis that subjects yawn more while observing uninteresting than while observing interesting stimuli by comparing the yawns produced to two stimuli that differed in interest. Subjects viewed either a 30-min videotape of rock videos, an interesting and complex visual and auditory stimulus for most college students, or a 30-min videotape of an unchanging color-bar test pattern that had no audio channel, a very uninteresting stimulus.

We gratefully acknowledge the statistical assistance of Marilyn Demorest and the editorial comments of Theodore Dembroski. Requests for reprints should be sent to Robert R. Provine at the Department of Psychology, University of Maryland Baltimore County, Catonsville, MD 21228.

\section{METHOD}

\section{Subjects}

Thirty-two subjects ( 16 males and 16 females), mostly college freshmen between 17 and 19 years of age, volunteered to earn experimentparticipation credit in an introductory psychology class.

\section{Procedure}

Subjects participated in two experimental sessions that were scheduled at least 2 days apart. In Session 1, each subject viewed either a 30-min videotape of rock and popular music performances, a complex audiovisual stimulus of interest to most college students, or an unchanging 30 -min color-bar test pattern that had no audio channel, a very uninteresting stimulus. In Session 2, each subject viewed the stimulus not presented to him/her during Session 1 . The order of stimulus presentation was counterbalanced. Subjects were tested individually.

Subjects were seated behind a desk in a small, sound-attenuated room (floor dimensions $2.5 \times 3.1 \mathrm{~m}$ ) and were told to observe a video monitor screen $(53 \mathrm{~cm}$ diagonal) that was approximately $1.5 \mathrm{~m}$ distant. Instructions were provided by the monitor via videotape by a college-age female. Subjects were told

$$
\begin{aligned}
& \text { to record your yawns, if any should occur, by pressing the button on } \\
& \text { the box on the table in front of you. Press the button when you inhale } \\
& \text { at the start of a yawn and keep the button depressed until you finish } \\
& \text { exhaling at the end of a yawn. You will be recording your own activity. } \\
& \text { During a session, you will not be observed in any way. }
\end{aligned}
$$

Subjects were then shown one of the two 30-min stimulus tapes. Subjects' self-reported yawning responses were recorded with an EsterlineAngus event recorder.

The present instructions to subjects were briefer than those used previously (Provine, 1986) because extensive instructions may contain a variety of yawn-related stimuli capable of evoking yawns that can obscure between-group differences. The abbreviated instructions may reduce the precision of the measurement of yawn duration, but will not affect the measurement of the variable of primary interest, yawning frequency.

\section{RESULTS}

Subjects viewing the color-bar test pattern without an audio track performed significantly more yawns than those viewing the music video [mean $=5.78$ vs. $3.41, F(1,28)$ $=4.26, p<.05]$. For the small subset of 14 of the 32 subjects who yawned in both conditions and for whom it was, therefore, possible to compare yawn duration, viewers of the test pattern performed longer yawns than viewers of the music video [mean $=3.79$ vs. $3.05 \mathrm{sec}$, 
$F(1,10)=5.39, p<.05]$. Neither gender nor the order of conditions had any effect on yawn frequency, but there was a gender difference for yawn duration. For males the duration was $4.05 \mathrm{sec}$, whereas for females it was $2.95 \sec [F(1,10)=7.59, p<.02]$.

\section{DISCUSSION}

The present analysis confirms the folk belief that people yawn more during uninteresting than interesting events. A positive correlation between yawning and the drowsiness experienced immediately before and after sleeping is reported elsewhere (Provine, Hamernik, \& Curchack, 1986). Taken together, these results for stimulus interest and sleeping times provide empirical support for the recognition of the yawn as a paralinguistic signal for drowsiness, fatigue, disinterest, and boredom.

Yawning frequency and duration were both less in the interesting than in the uninteresting stimulus condition. As previously shown, yawns may be performed at rates ranging from zero to several yawns per minute (Provine, 1986). However, the yawn is a stereotyped action pattern that is performed at so-called "typical intensity"; extremely short or fractional yawns are seldom, if ever, produced (Provine, 1986). Although there are more constraints on the duration than the frequency of yawns, the present finding of shorter yawns by observers of interesting stimuli suggests that there is at least modest context-induced variability in yawn duration. A gender difference in yawn duration was also detected; males performed longer yawns than females. The relatively short yawns reported by all groups in the present study may be due to the shorter than usual training and instruction of subjects (cf. Provine, 1986), a modification of procedure that was made to reduce the probability of indirectly priming the yawning response (see Method). Future analyses of yawn duration should use direct measures of the inspiration and expiration of yawns or videotape analyses of yawn movements to avoid possible confounds that may be attributable to the self-report procedure. For example, subjects may concentrate more on interesting than on uninteresting stimuli and, thus distracted, report but not perform shorter yawns. These concerns about the self-report of yawn duration are not relevant to the measurement of yawn frequency, the variable of principal concern in the present study.

\section{REFERENCES}

BARBizet, J. (1958). Yawning. Journal of Neurological \& Neurosurgical Psychiatry, 21, 203-209.

Heusner, A. P. (1946). Yawning and associated phenomena. Physiological Review, 25, 156-168.

KATAOKA, J. (1975). Free physical movements during waiting while standing and sitting. Journal of Human Ergology, 4, 3-13.

KishidA, K. (1973). Temporal change of subsidiary behavior in monotonous work. Journal of Human Ergology, 2, 75-89.

Provine, R. R. (1986). Yawning as a stereotyped action pattern and releasing stimulus. Ethology, 72, 109-122.

Provine, R. R., Hamernik, H. B., \& Curchack, B. C. (1986). Yawning, stretching, and sleeping. Unpublished manuscript.

SAKAI, K., \& TAKAHASHI, Y. (1975). Driving and subsidiary behavior of taxi drivers working alternate day shifts. Journal of Human Ergology, 4, 115-127.

(Manuscript received for publication July 11, 1986.) 